\title{
O PENSAR DE DOCENTES QUE ATUAM NO CURSO DE CIÊNCIAS BIOLÓGICAS A RESPEITO DO QUE É HISTÓRIA DA CIÊNCIA E DO USO DA MESMA EM SUA PRÁXIS
}

\author{
THINKING OF TEACHERS WHO ACT IN THE COURSE OF BIOLOGICAL SCIENCES \\ IN RESPECT OF WHAT IS HISTORY OF SCIENCE AND THE USE OF THE SAME IN \\ ITS PRACTICE
}

\author{
Maíra Luana Santos Souza* \\ mairalssouza@gmail.com \\ Dulcineia Ester Pagani Gianotto* \\ depgianoto@uem.br \\ Carlos Alberto de Oliveira Magalhães Júnior * \\ juniormagalhaes@hotmail.com
}

* Universidade Estadual de Maringá - Maringá/PR - Brasil

\begin{abstract}
Resumo
A abordagem da História da Ciência no ensino é essencial para uma formação científica mais realista, humana e contextualizada, ou seja, não deformada. No entanto, para alcançar-se essa formação é imperativo conhecer o que os educadores que trabalham no ensino superior pensam sobre a História da Ciência. Nesse sentido, o objetivo desta pesquisa foi conhecer e analisar a concepção sobre História da Ciência e seu uso por parte dos docentes envolvidos no processo de formação inicial do curso de Ciências Biológicas na Universidade Estadual de Maringá. Os dados são oriundos da aplicação de um questionário, realizado no ano de 2013 , com os docentes efetivos do curso de Ciências Biológicas e que contemplam sete departamentos. O perfil dos participantes foi traçado e analisaram-se três questões abertas com base na Análise de Conteúdo Temático Categorial. Os resultados nos alertaram sobre as ideias deformadas e ingênuas a respeito do que é História da Ciência e seu uso na formação inicial.
\end{abstract}

PALAVRAS-CHAVE: formação inicial. Interdisciplinaridade. Ensino de Ciências. Questionário

\begin{abstract}
The History of Science and its approach to teaching are essential for a scientific training more realistic, human and contextualized, in other words, not deformed. However, to achieve such training is imperative to know what educators think about the history of science at the higher education. In this sense, the aim of this study was to identify and analyze the notion of history of science and its use by teachers involved in the initial training of students from the Biological Sciences at University of Maringá. The data are from a questionnaire, conducted in 2013, with teachers who teach classes for the course mentioned and include seven departments. The profile of participants was drawn and analyzed three open questions based on the Thematic Content Analysis Categorical. The results have warned us about the deformed and ingenuous ideas about what is History of Science and its use in training of the students.
\end{abstract}

Keywords: initial training. Interdisciplinarity. Science teaching. Quiz. 


\section{INTRODUÇÃO}

Apesar de muitos estudiosos tentarem definir o que é História da Ciência (HC), inclusive se a denominação adequada é "História da Ciência" ou "Histórias das Ciências", não há um consenso, visto que essas discussões são complexas. No entanto, isso não nos impede de avançar na argumentação desde que nos fundamentemos em autores da área.

Podemos considerar que o surgimento da HC se deu no século XVII juntamente com a Ciência moderna e no interior dessa própria Ciência, sendo assim, ela possuiu, num primeiro momento, o perfil de justificativa da Ciência que estava se formando (ALFONSO-GOLDFARB, 2004; FERREIRA; MARTINS, 2009).

De acordo com Ferreira e Martins (2009), a HC é uma área de pesquisa consolidada tanto no exterior como no Brasil. Ela não é considerada um conjunto de biografias de gênios da Ciência que tiraram suas ideias e contribuições do nada com um método universal, nem um conjunto de relatos cronologicamente organizados sobre eventos ou episódios marcantes que foram facilmente aceitos pela sociedade científica, mas sim uma área de estudos complexos que procura esclarecer em profundidade os múltiplos aspectos e interrelações envolvidos na construção de um conhecimento científico de uma dada época e dentro do seu próprio contexto de origem (MARTINS, 1993; MARTINS, 2005; FERREIRA; MARTINS, 2009).

A partir da leitura de autores como Beltran, Saito e Trindade (2010), Ferreira e Martins (2009), Martins (2005) e Martins (2006) algumas considerações a respeito da HC puderam ser elaboradas: tratase de uma área do conhecimento especializada, que detém uma terminologia adequada, assim como contornos bem definidos por métodos e objetos próprios de investigação, mas, também é interdisciplinar, pois, está “em constante comunicação com essas áreas que emprestaram seus conhecimentos à História da Ciência” (ALFONSO-GOLDFARB, 2004, p.9).

Segundo Alfonso-Goldfarb (1994)

[...] os estudos em História da Ciência dependem de especialistas, pois diferentemente do que pensa o senso comum, não basta juntar História e Ciência para que o resultado final seja provavelmente história da ciência, pois da junção de duas coisas forma-se uma terceira, com características próprias, diferente daquelas que lhe deram origem (ALFONSO-GOLDFARB, 1994 apud BELTRAN; SAITO; TRINDADE, 2010, p.121).

Observamos na literatura que existem diversas subáreas e vários tipos de enfoques distintos em HC, pois esta representa, juntamente com a Filosofia da Ciência um vasto campo de pesquisa que vem construindo suas bases teóricas e suas especificidades sendo inclusive uma área do conhecimento com 
implicações para a Didática das Ciências, relacionando-se a questões de várias ordens: aspectos teóricos, quando trabalha a partir de elementos do campo da $\mathrm{HC}$, e aspectos mais práticos e aplicados, quando é pensada tanto como conteúdo das disciplinas científicas quanto como estratégia didática (MARTINS, 2005; MARTINS, 2007). Independente do campo de pesquisa, a abordagem historiográfica presente na HC depende do ponto de vista e da formação do pesquisador que faz uso da história (MARTINS, 2005; OLIVEIRA; SILVA, 2011, 2012)

\section{1 - HISTÓRIA DA CIÊNCIA NO ENSINO}

Há alguns anos, educadores de várias partes do mundo perceberam a importância da utilização da HC no ensino de Ciência em todos os níveis, sendo sua inclusão constantemente defendida por muitos pesquisadores da área (MARTINS, 2006). No entanto, outras abordagens da educação, de caráter mais técnico, ganharam relevância nos últimos anos (PEREIRA et al, 2009).

Atualmente, de acordo com Cachapuz et al (2004, p. 364), não existe "uma teoria geral que unifique e dê coerência a conceitos, fenômenos e circunstâncias relativas ao ensino, à aprendizagem e à formação". No entanto, as abordagens focadas na transmissão conceitual e técnica, como também as mudanças ocorridas no mundo, contribuíram para uma crise mundial na educação científica. Com isso, a HC voltou à pauta da discussão como uma rica alternativa para renovar o ensino (MATTHEWS, 1995; CARNEIRO; GASTAL, 2005; PEREIRA et al, 2009).

A articulação entre $\mathrm{HC}$ e ensino tem sido apresentada e apreciada tanto por educadores quanto historiadores da Ciência no exterior e aqui no Brasil, tendo como foco a abordagem histórico-filosófica dos conteúdos na formação do cientista e do professor, como representada pelo movimento CTS para o ensino de ciências (MARTINS, 2007; SAITO, 2010).

Saito (2010) ressalta que

[...] embora a HC seja uma mediadora para a aprendizagem de ciências, não é método de ensino, mas uma provedora de recursos que conduz à reflexão sobre o processo de construção do conhecimento científico (SAITO, 2010, p.4).

Não quer dizer que a HC, assim como a Filosofia e Sociologia da Ciência, possa substituir o ensino comum das ciências ou possua todas as respostas para essa crise do ensino contemporâneo. No entanto, Batista (2007) afirma, e nós concordamos que, segundo investigações e discussões, alguns consensos sobre HC podem ser estabelecidos (CASTRO, 1992; MATTHEWS, 1995; CARNEIRO; GASTAL, 2005; MARTINS, 2006; FERREIRA; FERREIRA, 2010; OLIVEIRA; SILVA, 2012):

a) torna as aulas mais desafiadoras e reflexivas, possibilitando o desenvolvimento do pensamento crítico para a tomada de decisões tecno-científicas; 
b) humaniza as ciências e o conteúdo ensinado ao aproximá-los dos interesses pessoais, éticos, culturais e políticos da comunidade;

c) desmistifica o conhecimento científico, sem negar seu valor;

d) explicita as relações entre dogma, sistema de crenças e racionalidade científica;

e) ajuda a superar o mar de falta de significação de fórmulas e equações, pois pode contribuir para um entendimento mais integral da matéria científica ao evidenciar seu carácter mutável e contextos de desenvolvimento;

f) melhora a formação do professor, auxiliando o entendimento da estrutura das ciências e o lugar das mesmas na nossa organização intelectual;

g) torna o conhecimento científico mais interessante, acessível e compreensível;

h) permite uma visão ampliada dos conceitos, dos problemas e de suas resoluções, inclusive relacionando-os interdisciplinarmente;

i) seu estudo pode conduzir a ideias inovadoras e a uma nova visão de mundo e da cultura científica, validando a relação cultura-intelectualidade;

j) apresenta uma visão mais realista e inteligível a respeito da Natureza da Ciência (NDC), permitindo formar uma visão mais concreta dos procedimentos, métodos e limitações da ciência;

k) apresentar-se como fio condutor de construções empreendidas pelos alunos.

É importante frisar que evocar a HC para iluminar o ensino apresenta algumas restrições e devemos tomar alguns cuidados. As três questões colocadas por Bizzo (1992) são: 1) que "a idéia do passado auxiliando na compreensão do presente pressupõe a existência de um continuum entre um momento e outro", o que não ocorre sempre. Além disso, a rivalidade revelada na maneira pela qual as teorias se sucedem e a seleção parcial que alguns cientistas fazem do passado para explicar o presente quando fazem uma construção útil e simplificada do conhecimento válido do ponto de vista da atualidade (tendência denominada whiggismo), podem levá-los a deformações do desenvolvimento científico; 2) que existem relações de hierarquia e complexidade entre o passado e o presente, as quais são, na realidade, consequência de falácias, modelos cumulativos do desenvolvimento científico e tendência de inocentar o cientista por não ter percebido a emergência de teorias emergentes de seu tempo; 3 ) elaborações teóricas que admitem que os estudantes explicam determinados fenômenos utilizando elementos parecidos com o de cientistas de outros períodos, restringindo o número de alternativas para a reconstrução do conhecimento científico e podendo conduzir a propostas historicistas ou recapitulacionistas, buscando no passado da Ciência a orientação para o presente do ensino. 


\section{2 - HISTÓRIA DA CIÊNCIA NA FORMAÇÃ̃ INICIAL}

O trabalho dos historiadores da Ciência nos últimos sessenta anos (MARTINS, 2006) nos abriu os olhos para certas concepções ingênuas sobre as ciências e o que ocorre na pesquisa científica, mas, infelizmente, esse conhecimento não se difundiu adequadamente no ensino superior e educação básica. Martins (2006) sugere que esse talvez seja o momento adequado para introduzi-lo na educação científica de todos os níveis, começando pela formação de docentes e do pessoal de nível superior, para depois atingir os outros níveis e uma população mais ampla.

Porém, como afirma Beltran, Saito e Trindade (2010, p.131) "apenas o reconhecimento da importância que a história da ciência teria no ensino não garante a necessária construção de interfaces e propostas viáveis para a sala de aula".

Carneiro e Gastal (2005), ao analisarem três coleções de livros de Biologia do ensino médio e alguns livros universitários usados em cursos de formação de professores, evidenciaram concepções de História da Biologia que reforçam uma imagem ingênua da ciência e de sua história, a qual vem sendo combatida:

a) histórias anedóticas: histórias curiosas e pouco divulgadas, geralmente, centradas na biografia de cientistas e em eventos fortuitos, sem contextualização histórica;

b) linearidade do conhecimento científico: sucessão cronológica e genealógica de episódios históricos que conduz a uma ideia de que o conhecimento científico atual é resultado definitivo e linear de conhecimentos preexistentes, omitindo e desvalorizando certos momentos, pessoas e conhecimentos;

c) consensualidade na construção do conhecimento científico: quando são apresentadas apenas concordâncias ou quando os pontos de vista conflitantes são apresentados, em geral, de modo a reforçar a ideia de visões corretas e equivocadas;

d) ausência do contexto histórico mais amplo: nesse caso

[...] não se encontram referências ao contexto histórico-social em que trabalhavam os cientistas, à influência das idéias vigentes à época em outros campos do conhecimento nem às influências e implicações políticas das idéias que estavam sendo geradas pela ciência (CARNEIRO; GASTAL, 2005, p.38).

Complementando essa sequência de imagens ingênuas, acrescentamos o paralelismo ingênuo estabelecido por alguns docentes entre a construção do conhecimento pelo aluno e a construção do conhecimento na Ciência, observada por Castro (1992) em sua pesquisa com um curso de Ensino Médio. De acordo com esse autor (Castro 1992, p. 235), deve ser estabelecido um diálogo, não paralelismo, entre essas construções, para "desvelar a construção do conhecimento científico como um trabalho de 
questionamento, de contraposição de ideias, de refinamento da visão de cada um sobre certos aspectos". Outra finalidade é amenizar a busca de um produto final, fórmula mágica ou definição para ser anotada e memorizada.

A abordagem interdisciplinar da $\mathrm{HC}$ na formação inicial de Ciências Biológicas, tanto para a habilitação de licenciatura quanto de bacharelado, pode vir a mitigar: a disseminação de concepções desatualizadas; práticas alienadas; motivações extrínsecas dos estudantes, ou seja, motivadas por recompensas ou punições à atividade proposta e o conhecimento envolto por uma visão instrumental, ao invés de "necessidade humana de ampliação de consciência e compreensão do mundo" (FERREIRA; FERREIRA, 2010, p.8).

Castro (1992) expõe que essa abordagem nesse nível de ensino parece apontar uma função quase reguladora da $\mathrm{HC}$, a qual pode propiciar questões de natureza explicativa, atitudinal ou meramente informativa.

A construção de interface entre $\mathrm{HC}$ e ensino não se dá com muita facilidade por vários motivos. Martins (2006) argumenta sobre três principais barreiras: 1) carência de número suficiente de professores com formação adequada para pesquisar e ensinar de forma correta a HC; 2) falta de material didático adequado para o ensino; e 3) equívocos a respeito da própria natureza da $\mathrm{HC}$ e seu uso na educação. De acordo com Beltran, Saito e Trindade (2010, p.121) "talvez o fator mais significativo desta dificuldade seja o pequeno número de historiadores da ciência existentes no Brasil”.

É importante salientar que ainda falta um maior número de estudos e análises críticas que possibilitem uma avaliação sobre como e se a perspectiva da HC deve ser trabalhada e em que contextos, nos diferentes níveis de escolaridade (CARNEIRO; GASTAL, 2005; MARTINS, 2006).

Partindo do pressuposto de que a HC é essencial na formação inicial dos discentes de Ciências Biológicas e que deve ser apresentada numa perspectiva mais realista, humana, inteligível, contextualizada e científica, em outras palavras, atualizada com o paradigma vigente de Ciência, é imperativo conhecer o que os educadores pensam sobre a $\mathrm{HC}$ no nível superior. Nesse sentido, objetivamos nessa pesquisa conhecer e analisar as concepções sobre $\mathrm{HC}$ e seu uso na prática dos docentes envolvidos no processo de formação inicial do curso de Ciências Biológicas na Universidade Estadual de Maringá (UEM).

\section{3 - METODOLOGIA}

Dentro de uma abordagem de pesquisa qualitativa, adotamos o questionário como ferramenta investigativa devido aos objetivos e às características dos sujeitos: as concepções dos professores do curso de Ciências Biológicas a respeito da História da Ciência e seu uso na formação inicial.

\section{1 - DELINEAMENTO AMOSTRAL}


A população pesquisada foi composta de professores da UEM que ministraram aulas para o curso de Ciências Biológicas, integral e noturno no ano de 2013, os quais contemplam tanto o departamento de Ciências Biológicas (DBI) quanto os demais departamentos presentes no Projeto Pedagógico do curso, atualizado pela Resolução $\mathrm{n}^{\circ}$ 044/2010-CI/CCB (UEM, 2010). O levantamento feito junto aos departamentos revelou um total de 79 docentes distribuídos heterogeneamente em cada um dos dez departamentos. Para a amostra, foram selecionados apenas os docentes efetivos e em exercício no ano de 2013. Adotamos esse critério de classificação para obtermos, na medida do possível, apenas as opiniões dos professores que tinham envolvimento maior no currículo do curso e na instituição. A amostra inicial da pesquisa foi de 54 docentes, porém a amostra efetivamente entrevistada correspondeu a 35 (Quadro 1). Portanto esta investigação abrangeu os seguintes departamentos: Biologia Celular e Genética (DBC); Bioquímica (DBQ); Departamento de Ciências Básicas da Saúde (DBS); Ciências Morfológicas (DCM); Física (DFI); Ciências Fisiológicas (DFS) e Geografia (DGE). Essa diminuição amostral ocorreu devido à dificuldade em encontrar docentes, resistência em participar da pesquisa, professores fora de exercício por diversas razões, desatualização de alguns departamentos sobre os docentes que ministravam aula para o curso em estudo e porque duas disciplinas do curso só serão ofertadas no ano de 2014.

Quadro 1. Quantidade de docentes por departamento na amostra inicial e na amostra efetivamente entrevistada.

\begin{tabular}{|c|c|c|}
\hline Departamento & $\begin{array}{c}\text { Quantidade } \\
\text { inicial }\end{array}$ & $\begin{array}{c}\text { Quantidade } \\
\text { entrevistada }\end{array}$ \\
\hline DBC & 5 & 2 \\
\hline DBI & 28 & 20 \\
\hline DBQ & 1 & 1 \\
\hline DBS & 8 & 4 \\
\hline DCM & 3 & 2 \\
\hline DES & 1 & 0 \\
\hline DFI & 2 & 1 \\
\hline DFS & 4 & 4 \\
\hline DGE & 1 & 1 \\
\hline DQI & 1 & 0 \\
\hline Total & $\mathbf{5 4}$ & $\mathbf{3 5}$ \\
\hline
\end{tabular}

Fonte: Elaboração das autoras. 


\section{2 - INSTRUMENTO PARA COLETA DE DADOS}

O questionário foi elaborado de acordo com as recomendações de Gil (2012) e Marconi e Lakatos (2010) e compunha onze questões. Sua aplicação ${ }^{1}$ foi realizada por meio impresso e ocorreu entre os meses de Setembro e Novembro de 2013.

O pré-teste do questionário foi realizado com a finalidade de verificar se este apresentava fidedignidade, validade e operatividade (MARCONI; LAKATOS, 2010). Este teste-piloto foi feito entrevistando-se três professores não efetivos. Dentre os dezenove docentes não efetivos da população, três foram sorteados aleatoriamente após ordenação alfabética, um do DBC e os outros dois do DQI. Após essa etapa, reformulamos as questões um, sete, nove e onze, além de acrescentar as questões três e seis.

\section{3 - ANÁLISE E INTERPRETAÇÃO DOS DADOS}

Os questionários respondidos pelos docentes que assinaram o Termo de Consentimento tiveram suas respostas transcritas e analisadas.

Primeiramente elaboramos o perfil dos participantes e em seguida, analisamos e interpretamos apenas as questões 5, 9 e 11 com base na Análise de Conteúdo Temático Categorial de Laurence Bardin, em virtude da extensão do questionário. As demais questões serão trabalhadas em artigo posterior.

Essa metodologia de análise dos dados não leva em consideração necessariamente todo o texto, sendo aplicável em significações manifestas e simples, as quais obtivemos com a aplicação dos questionários. Além disso, as unidades de significação que foram codificadas e serviram de recorte para o objetivo analítico escolhido, denominadas Unidades de Registro (UR), corresponderam a temas, os quais são definidos por Berelson como:

Uma afirmação acerca de um assunto. Quer dizer, uma frase, ou uma frase composta, habitualmente um resumo ou uma frase condensada, por influência da qual pode ser afectado um vasto conjunto de formulações singulares (BERELSON, 1971 apud BARDIN, 2004, p.105).

Conforme Moraes e Galiazzi (2013) argumentam, não se trata de um conjunto rígido de procedimentos, mas sim um conjunto de orientações abertas e reconstruídas em cada trabalho. Esses

\footnotetext{
${ }^{1}$ Mediante Termo de Consentimento (Anexo 2) assinado pelos sujeitos ao aceitarem voluntariamente participar da pesquisa, o Comitê Permanente de Ética de Pesquisa com Seres Humanos (COPEP/UEM) autorizou a realização da presente investigação (16469413.0.0000.0104). Do mesmo modo, buscando sigilo das pessoas envolvidas na pesquisa adotamos como critério de referência a esses sujeitos a legenda Pn, sendo n o número atribuído ao profissional em ordem alfabética.
} 
mesmos autores ainda afirmam que, embora a Análise de Conteúdo fosse muito presa à lógica formal em sua origem, ela evoluiu ao longo dos últimos anos, assumindo gradativamente pressupostos da lógica dialética e concebendo a realidade como dinamicamente construída.

Os discursos passaram por três fases de análise: 1) pré-análise, que tem por objetivo sistematizar as ideias iniciais do texto, de maneira a facilitar as operações sucessivas, envolvendo escolha dos materiais analisados, formulação de hipóteses e objetivos e elaboração de indicadores que fundamentem a análise final; 2) exploração do material, que consiste na administração sistemática das decisões tomadas na fase anterior, ou seja, após a "leitura flutuante" e escolha de índices organizados em indicadores que codifiquem os dados, os quais são transformados sistematicamente e agregados em unidades (unitarização); 3) tratamento dos dados, que compreende a inferência e a interpretação.

O interesse nesse tipo de análise, como afirma Bardin (2004, p. 38) "não reside na descrição dos conteúdos, mas sim no que estes nos poderão ensinar após serem tratados [...]”, pois a intenção é a inferência de conhecimentos relativos às condições de produção/recepção dessas mensagens a partir de indicadores.

Na pré-análise, optamos por analisar todos os questionários respondidos pelos docentes efetivos no curso e instituição pesquisados, a respeito do mesmo tema e objetivos. Dessa forma, contemplamos as regras de representatividade, exaustividade, homogeneidade e pertinência.

Em virtude de nossa análise ser temática e qualitativa, da característica dos dados obtidos e do instrumento de coleta de dados, não levantamos indicadores na fase de exploração do material, e sim codificamos os dados por meio das Unidades de Análise previamente elaboradas. Estas unidades compreenderam Unidades Temáticas de Contexto (UC), que são segmentos de mensagens com função de tornar compreensíveis as Unidades de Registro a serem codificadas (BARDIN, 2004; MOREIRA; CALEFFE, 2008; SANTOS, 2012).

$\mathrm{Na}$ fase de tratamento dos resultados, inferência e interpretação, descrevemos os mesmos e, posteriormente, construímos um texto de análise, dialogando com os referenciais teóricos, para identificar as concepções dos participantes da pesquisa.

Vale ressaltar que, em nenhum momento, a análise dos dados visou explanar as possíveis causas relacionadas às ideias dos entrevistados.

\section{4 - RESULTADOS E DISCUSSÃO}

\section{1 - QUESTÕES ELABORADAS E SUAS UNIDADES DE CONTEXTO E REGISTRO}

As questões de número 1 a 4 visaram apenas caracterizar a amostra, sendo assim, apresentamos e explicamos as questões 5, 9 e 11, assim como suas Unidades de Contexto e Registro prévias e emergentes. Estas unidades receberam a mesma numeração da questão a partir da qual foram elaboradas. 
A questão 5 "O que é História da Ciência (HC) para você?” foi proposta com o intuito de conhecer as concepções dos participantes a respeito da HC, reunindo em sua respetiva Unidade de Contexto - UC5 os fragmentos textuais que indicam concepções a respeito de HC. Os dados analisados nessa unidade foram organizados em nove Unidades de Registro (UR5) prévias possíveis: Em conformidade (UR 5.1); Biográfica (UR 5.2); Experimental (UR 5.3); Linear (UR 5.4); Anedótica (UR 5.5); A-problemática (UR 5.6); A-histórica (UR 5.7); Desconhecimento (UR 5.8); Não contempla a pergunta (UR 5.9).

A questão 9 "Em sua opinião, o que deveria ser discutido em sua disciplina, em relação a $\mathrm{HC}$, durante o curso de biologia?" foi proposta com o intuito de conhecer o que os participantes pensam que deveria ser discutido sobre $\mathrm{HC}$ em sua disciplina e sua respetiva Unidade de Contexto - UC9 - reuniu os fragmentos textuais em oito Unidades de Registro (UR9) prévias possíveis: Em conformidade (UR 9.1); Biográfica (UR 9.2); Experimental (UR 9.3); Linear (UR 9.4); Anedótica (UR 9.5); A-problemática (UR 9.6); A-histórica (UR 9.7); Não contempla a pergunta (UR 9.8).

A questão 11 "Se você assinalou "sim" na questão anterior, responda de que forma utiliza/utilizou HC." foi proposta com o intuito de conhecer de que maneira a $\mathrm{HC}$ é utilizada pelos participantes nas disciplinas que ministram. Logo, sua Unidade de Contexto - UC11- reuniu os fragmentos textuais em oito Unidades de Registro (UR11) prévias possíveis, com as mesmas denominações elaboradas para a questão 9.

\section{2 - PERFIL DOS PARTICIPANTES}

Do total de 35 docentes entrevistados, 21 são licenciados, nove são bachareis e cinco apresentam ambas as habilitações (Quadro 2).

Como a pesquisa foi realizada com os docentes que ministram aula para o curso de Ciências Biológicas, era esperada que grande parte dos participantes fosse formada nessa área, fato verificado.

Quadro 2. Habilitação dos docentes.

\begin{tabular}{|l|c|}
\hline \multicolumn{1}{|c|}{ Habilitação } & Quantidade \\
\hline Licenciados & 21 \\
\hline Bachareis & 9 \\
\hline $\begin{array}{l}\text { Licenciados e } \\
\text { bachareis }\end{array}$ & 5 \\
\hline
\end{tabular}

Fonte: Elaboração das autoras.

Conforme mostra a Figura 1a, a maioria (91\%) é graduada na área de Ciências Biológicas (na qual agrupamos Ciências Biológicas, Fisiológicas, Morfológicas, Genética, Bioquímica e Geologia), sendo os demais formados em Ciências da Saúde (3\%), Agrárias (3\%) e Exatas (3\%). Em relação à pós- 
graduação, a proporção é similar (Figura 1b), no entanto a área de Ciências Agrárias é substituída pela de Ciências Humanas, que passa a corresponder a $(6 \%)$.

Figura 1. Área de formação na graduação (a) e pós-graduação (b).

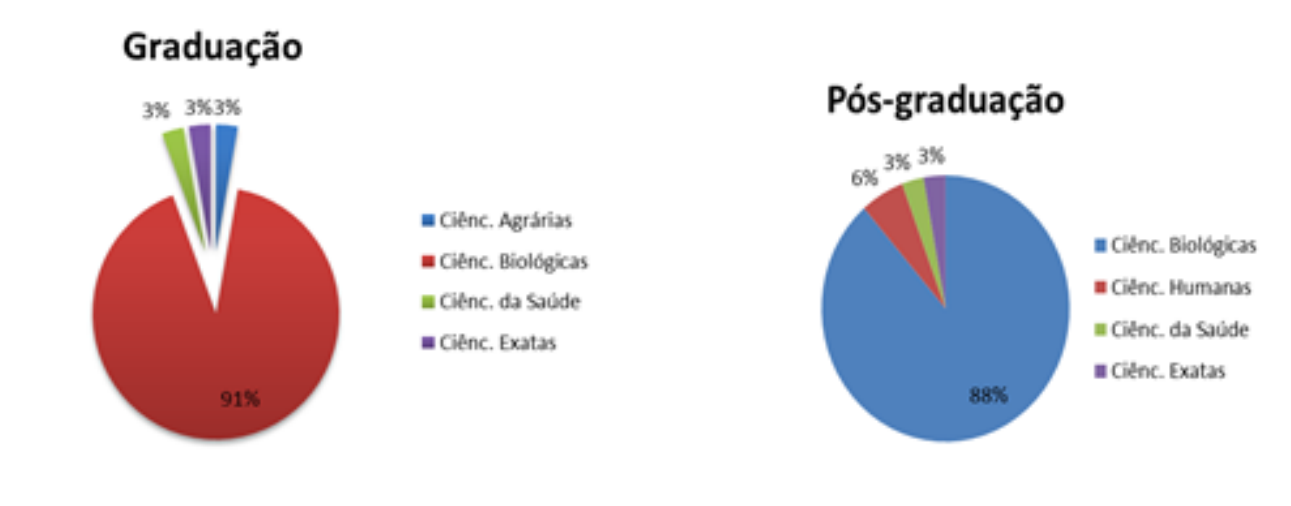

Fonte: Elaboração das autoras.

\section{5 - CONCEPÇÕES SOBRE HISTÓRIA DA CIÊNCIA E SUA UTILIZAÇÃO NA FORMAÇÃO INICIAL}

Na UC5 Noções de História da Ciência, unitarizamos os registros obtidos com a Questão 05 que permitiram identificar as concepções dos participantes a respeito da HC entre as cinco categorias criadas. A categoria com maior quantidade de registros foi a Cumulativa (20 registros), seguida pela Em conformidade (8), Consensual (5) e Não contempla a pergunta (2). No Quadro 3 apresentamos alguns dos fragmentos textuais obtidos, agrupados em suas UR correspondentes e acompanhados do número de registros e as frequências relativas de cada UR da UC5.

Quadro 3. Frequências relativas das URs referentes aos registros da Questão 05 e alguns fragmentos textuais.

\begin{tabular}{|l|l|}
\hline \multicolumn{2}{|c|}{ UC5 - Noções de História da Ciência } \\
\hline \multicolumn{1}{|c|}{ UR } & \multicolumn{1}{|c|}{ Quantidade de registros e fragmentos textuais } \\
\hline 5.1 Em conformidade & $\begin{array}{l}\text { 08 registros } \mathbf{( 2 2 , 9 \% )} \\
{[\ldots] \text { uma linha de pesquisa voltada para a investigação dos }} \\
\text { contextos históricos da produção científica e sua aplicação no } \\
\text { ensino de ciências [...] uma vertente, ou abordagem } \\
\text { epistemológica para o ensino de disciplinas científicas[...]. (P18) }\end{array}$ \\
\hline 5.2 Cumulativa & $\begin{array}{l}\text { 20 registros }(\mathbf{5 7 , 1 \%}) \\
{[\ldots] \text { relacionada com a observação e explicação dos fenômenos }} \\
\text { naturais ao longo do tempo, de forma que, com a evolução das } \\
\text { ideias e aumento de conhecimento ou informaçães, contribuiriam }\end{array}$ \\
\hline
\end{tabular}




\begin{tabular}{|c|c|}
\hline & $\begin{array}{l}\text { para o nível de conhecimento científico atual. (P1) } \\
\text { [...] refere-se ao registro cronológico dos acontecimentos e } \\
\text { descobertas científicas relevantes e da vida pessoal das } \\
\text { personalidades que inovaram a ciência em suas várias áreas. } \\
(\mathrm{P} 34)\end{array}$ \\
\hline 5.3 Consensual & $\begin{array}{l}\text { 05 registros }(\mathbf{1 4 , 3 \% )} \\
\text { [...] aborda o caminho percorrido desde o início da ciência na } \\
\text { humanidade até hoje, com toda metodologia científica já bem } \\
\text { estabelecida. }(\mathrm{P} 20)\end{array}$ \\
\hline $\begin{array}{l}5.4 \text { Não contempla a } \\
\text { pergunta }\end{array}$ & $\begin{array}{l}\mathbf{0 2} \text { registros } \mathbf{( 5 , 7 \% )} \\
\text { Até a Idade Média o conhecimento era controlado inteiramente } \\
\text { pela religião e tinha como finalidade comprovar a doutrina } \\
\text { imposta pela igreja. Com a ascenção da burguesia } \\
\text { (Resnascimento) a sociedade rompe com as velhas tradições } \\
\text { tornando o conhecimento científico mais individualizado e a } \\
\text { religião tem seu caráter mais íntimo, mais o menos como ocorre } \\
\text { atualmente. }(\mathrm{P} 35)\end{array}$ \\
\hline
\end{tabular}

Fonte: Elaboração das autoras.

Apesar de Martins (2006) afirmar que há vários anos boa parte dos educadores perceberam a importância da utilização da HC no ensino de Ciência em todos os níveis, assim como as concepções ingênuas sobre a ciência e pesquisa científica, nossas análises dos fragmentos textuais da UC5 mostram que a difusão dessas pesquisas não se deu como o esperado. Porque essas concepções diferentes do paradigma vigente influenciam a noção sobre HC.

Na UC9 O que deveria ser discutido a respeito de História da Ciência, unitarizamos os registros que permitiram identificar o que os participantes pensam que deve ser discutido sobre HC em sua disciplina. No Quadro 4 apresentamos alguns dos fragmentos textuais obtidos, agrupados em suas UR correspondentes. Salientamos que para essa questão foi necessária a elaboração de duas Unidades Emergentes (UE):

Quadro 4. Frequências relativas das URs referentes aos registros da Questão 09 e alguns fragmentos textuais

\begin{tabular}{|l|l|}
\hline \multicolumn{2}{|c|}{ UC9 - O que deveria ser discutido a respeito de História da Ciência } \\
\hline \multicolumn{1}{|c|}{ UR } & \multicolumn{1}{|c|}{ Quantidade de registros e fragmentos textuais } \\
\hline 9.1 Em conformidade & $\begin{array}{l}\text { 03 registros } \mathbf{( 8 , 6 \% )} \\
{[\ldots] \text { importante nas discussões sobre o que é "Ciência”, ou seja, }} \\
\text { sobre sua natureza e também como enfoque metodológico [...]. } \\
(\mathrm{P} 18)\end{array}$ \\
\hline 9.2 Cumulativa & $\mathbf{1 9}$ registros $\mathbf{( 5 4 , 3 \% )}$ \\
\hline
\end{tabular}




\begin{tabular}{|c|c|}
\hline & $\begin{array}{l}\text { A história [...] desde Aristóteles até a atualidade. Como o } \\
\text { conhecimento da Fisiologia foi sendo alterada com o } \\
\text { desenvolvimento da tecnologia. (P17) }\end{array}$ \\
\hline 9.3 Consensual & $\begin{array}{l}\mathbf{0 3} \text { registros }(\mathbf{8 , 6 \% )} \\
\text { Na minha disciplina é possível relatar fatos que foram divisores } \\
\text { de água, com p/ exemplo a guinada na Sistemática após Linneu. } \\
\text { Além de mencionar outros eventos e naturalistas que mudaram o } \\
\text { rumo da HC. }(\mathrm{P} 3)\end{array}$ \\
\hline 9.4 Descontextualizada & $\begin{array}{l}\mathbf{0 2} \text { registros }(\mathbf{5 , 7 \%}) \\
{[\ldots] \text { trabalham constantemente com a origem das palavras, }} \\
\text { conceitos e significados [...]. (P6) }\end{array}$ \\
\hline 9.5 Espontânea & $\begin{array}{l}\mathbf{0 1} \text { registro }(\mathbf{2 , 9 \% )}) \\
\text { Não tem isso. Ela sempre está presente. }(\mathrm{P} 31)\end{array}$ \\
\hline 9.6 Equivalente & $\begin{array}{l}\text { 01 registro }(\mathbf{2 , 9 \% )} \\
\text { Creio que as colocações do item } 11 \text { respondem à presente. }(\mathrm{P} 4)\end{array}$ \\
\hline $\begin{array}{l}9.7 \text { Não contempla } \mathrm{a} \\
\text { pergunta }\end{array}$ & $\begin{array}{l}06 \text { registros }(\mathbf{1 7 , 1 \% )} \\
\text { Eu busco este interesse constante em nossas aulas. (P5) } \\
{[\ldots] \text { as discussões são abrangentes e necessárias. (P21) }}\end{array}$ \\
\hline
\end{tabular}

Fonte: Elaboração das autoras.

Estas abordagens diferentes do paradigma vigente e ultrapassadas, assim como outras listadas por Carneiro e Gastal (2005) são veiculadas e reforçadas por livros didáticos inclusive do ensino universitário, os quais, por sua vez, influenciam os livros direcionados ao ensino médio e a formação.

Como Castro (1992) defende, e nós concordamos, conhecer as ideias e buscar compreender o passado das mesmas pode ajudar o professor em formação a inteirar-se dos obstáculos para o desenvolvimento das ciências, podendo fazer com que ele não subestime a dificuldade de seus alunos, assim como reconhecer a complexidade de certos conceitos que ensina. Essa perspectiva histórica e crítica da Ciência também é fundamental para o bacharel em formação, pois, além de auxilia-lo no aprendizado de conteúdos e processos científicos, é fonte de conhecimento e estímulo para elaboração de teorias, metodologias e problemas de pesquisa para a realidade em que vive e a futura. De acordo com Oliveira e Silva (2011), a abordagem histórica permite inclusive a formação de cidadãos aptos para a tomada de decisões tecno-científicas.

Vale a pena ressaltarmos o fragmento textual exposto no Quadro 4, categoria Espontânea, por P31: "Não tem isso. Ela sempre esta presente". De acordo com Cachapuz (2004) depende de nós, professores e cidadãos, imprimirmos sentido as coisas tendo em vista a formação de cidadãos cientificamente cultos. Mantendo esse ponto de vista, a utilização da HC na educação não é algo espontâneo na prática docente, mas uma atitude consciente, pensada e refletida. Se encararmos os conteúdos de ciências como óbvios, as diversas redes de construção identificadas para dar suporte a teorias sofisticadas podem passar a ideia 
de algo natural e de compreensão imediata, passível de mera transmissão e não como conhecimento a ser elaborado (CASTRO, 1992).

Na UC11- O que é discutido/utilizado a respeito de História da Ciência, unitarizamos os registros que permitiram identificar quais abordagens a respeito de $\mathrm{HC}$ os participantes utilizam. No Quadro 5 apresentamos alguns dos fragmentos textuais obtidos, agrupados em suas UR correspondentes. Salientamos que para essa questão foi necessária a elaboração de uma UE: Indefinida.

Quadro 5. Frequências relativas das URs referentes aos registros da Questão 11 e alguns fragmentos textuais

\begin{tabular}{|c|c|}
\hline \multicolumn{2}{|c|}{ UC11 - O que é discutido/utilizado a respeito de História da Ciência } \\
\hline UR & Quantidade de registros e fragmentos textuais \\
\hline 11.1 Em conformidade & $\begin{array}{l}\mathbf{0 5} \text { registros }(\mathbf{1 4 , 3 \% )} \\
{[. . .] \text { que se conhece hoje é resultante de todo um processo que }} \\
\text { vem sendo desenvolvido e assim deve continuar. A iconização, a } \\
\text { idolatria, a dogmatização, o per refratário, entre outros, são } \\
\text { sérios problemas que devem ser combatidos, sempre no } \\
\text { entendimento do processo histórico. }(P 4)\end{array}$ \\
\hline 11.2 Cumulativa & $\begin{array}{l}13 \text { registros }(\mathbf{3 7 , 1 \% )} \\
\text { Esse tema é a parte inicial da disciplina onde é abordado o } \\
\text { início da classificação das plantas e para entender o atual } \\
\text { sistema utiliza-se como o conhecimento foi organizado e } \\
\text { sistematizado desde o homem primitivo até os dias atuais. (P10) }\end{array}$ \\
\hline 11.3 Descontextualizada & $\begin{array}{l}\text { 06 registros }(\mathbf{1 7 , 1 \% )} \\
\text { Sempre procuro mostrar os princípios norteadores que estejam } \\
\text { ligados a denominações, métodos ou até instrumentos que nos } \\
\text { levam a pensar como na atualidade. Por ex., porque alguns } \\
\text { termos são (ainda) usados; algumas pesquisas experimentais; } \\
\text { etc. }(\mathrm{P} 6)\end{array}$ \\
\hline 11.4 Espontânea & $\begin{array}{l}\text { 01 registro (2,9\%) } \\
\text { Quando eu falo em paradigmas, hipóteses, conservação, algas e } \\
\text { bioindicadores (envolvendo ecologia) necessariamente entro na } \\
\text { história da ciência: como era, como é, quem fez, quem segue } \\
\text { [...]. (P31) }\end{array}$ \\
\hline 11.5 Equivalente & $\begin{array}{l}\text { 04 registros }(\mathbf{1 1 , 4 \% )} \\
(\mathrm{P} 14),(\mathrm{P} 25),(\mathrm{P} 26),(\mathrm{P} 32) \text { Vide resposta } 9 .\end{array}$ \\
\hline $\begin{array}{l}\text { 11.6 Não respondeu a } \\
\text { pergunta }\end{array}$ & 04 registros $(11,4 \%)$ \\
\hline $\begin{array}{l}\text { 11.7 Não contempla a } \\
\text { pergunta }\end{array}$ & $\begin{array}{l}\text { 01 registros } \mathbf{( 2 , 9 \% )} \\
\text { Inicialmente, geralmente, nas primeiras aulas de cada disciplina } \\
\text { uma abordagem superficial é abordada. Porém, os programas }\end{array}$ \\
\hline
\end{tabular}


$\mid \begin{aligned} & \text { de biologia, devido à gama de conteúdo dentro de um tempo } \\ & \text { restrito é um limitante. }(\mathrm{P} 34)\end{aligned}$

Fonte: Elaboração das autoras.

É importante ressaltar o fragmento textual exposto no Quadro 5 por P11: “Através da utilização de slides apresento os personagens importantes da Zoologia (Aristóteles, Linnaeus...); conto de que forma algumas doenças foram descobertas e estudadas [...] Porém, confesso apresentar uma limitação pessoal sobre o assunto, de conteúdo e metodologias para tornar o assunto menos "teórico", e mais dinâmico". Em relação a isso, Saito (2010) comenta que a interação entre História da Ciência e Ensino ainda carece de bases teóricas mais sólidas. No entanto algumas propostas para aplicação em sala de aula têm sido, em sua maior parte, apresentadas como relatos e "ensaios". Dentre as propostas mais comuns estão o uso de fontes históricas, por meio de softwares, por exemplo; a reprodução de experimentos históricos e outras que tratam da natureza do conhecimento científico, associadas à epistemologia das ciências. A HC também pode fornecer subsídios aos educadores.

A partir desses resultados, reconhecemos como a visão e uso da abordagem histórica por meio da HC na educação científica dependem da concepção de Ciência do professor e da concepção e finalidades racionais do ensino de ciências (PESSOA JUNIOR, 1996; TAVARES, 2010). Dessa forma, como afirma Tavares (2010, p.15) “os objetivos traçados inicialmente é que determinarão (ou não) o uso da abordagem histórica, bem como a forma de trabalho com este enfoque".

\section{CONSIDERAÇÕES FINAIS}

A pesquisa qualitativa sobre a noção a respeito de História da Ciência e seu uso por parte dos docentes envolvidos na formação inicial do curso Ciências Biológicas mostrou-se satisfatória, pois observamos que apesar de haver um claro interesse com relação ao uso de HC no ensino, há uma falta de formação ou orientação para o uso adequado da mesma na formação científica e humana dos discentes.

Destacamos a necessidade de melhor difusão das pesquisas direcionadas a um ensino científico adequado à realidade atual, assim como a formação continuada dos docentes envolvidos no processo de formação inicial, para que eles se apropriem novos conhecimentos e ressignifiquem os já adquiridos

\section{REFERÊNCIAS}

BARDIN, L. (2004). Análise de Conteúdo. Lisboa, PT: Edições 70.

BATISTA, I.L. (2007). Reconstruções Histórico-Filosóficas e a pesquisa em Educação Científica e Matemática. In: NARDI, R. (Org.). A pesquisa em ensino de ciências no Brasil: alguns recortes. São Paulo: Escrituras, 257-272.

BELTRAN, M.H.R.; SAITO, F.; TRINDADE, L. dos S.P. (Org.). (2010). História da Ciência: tópicos atuais. São Paulo: Livraria da Física. 
BIZZO, N.M.V. (1992). História da ciência e ensino: onde terminam os paralelos possíveis? Em Aberto, 11, 55, 29-35.

CACHAPUZ, A. et al. (2004). Da educação em ciências às orientações para o ensino das ciências: um repensar epistemológico. Ciência \& Educação, 10, 3, 363-381.

CARNEIRO, M.H. da S. e GASTAL, M.L. (2005). História e filosofia das ciências do ensino de biologia. Ciência \& Educação, 11, 1, 33-39.

CASTRO, R.S. (1992). História da Ciência: investigando como usá-la num curso de segundo grau. Cad. Cat. Ens. Fís., 9, 3, 225-237.

FERREIRA, A.M.P. e FERREIRA, M.E. de M.P. (2010). A História da Ciência na formação de professores. História da Ciência e Ensino: construindo interfaces, 2, 1-13.

FERREIRA, J.M.H. e MARTINS, A.F.P. (2009). Disciplina de História e Filosofia da Ciência Material Didático - Ensino a Distância - Universidade Federal do Rio Grande do Norte.

GIL, A.C. (2012). Questionário. In: Métodos e técnicas de pesquisa social. São Paulo: Atlas, 121135.

MARCONI, M. de A. e LAKATOS, E.M. (2010). Técnicas de Pesquisa. In: Fundamentos de metodologia científica. São Paulo: Atlas, 2010, 157-197.

MARTINS, A.F.P. (2007). História e filosofia da ciência no ensino: há muitas pedras nesse caminho. Caderno Brasileiro de Ensino de Física, 24, 1, 112-131.

MARTINS, L. Al-Chueyr P. (2005). História da ciência: objetos, métodos e problemas. Ciência \& Educação, 11, 2, 305-317.

MARTINS, R. de A. (1993). Abordagens, métodos e historiografia da história da ciência. In: MARTINS, Â.M. (ed.). O tempo e o cotidiano na história. São Paulo: Fundação para o desenvolvimento da educação, 73-78.

MARTINS, R. de A. (2006). Introdução: a história das ciências e seus usos na educação. In: SILVA, C.C. (Org.). Estudos de história e filosofia das ciências: subsídios para aplicação no ensino. São Paulo: Livraria da Física, XVII-XXX.

MATTHEWS, M.R. (1995). História, filosofia e ensino de ciências: a tendência atual de reaproximação. Cad. Cat. Ens. Fís., 12, 3, 164-214.

MORAES, R. e GALIAZZI, M. do C. (2013). Análise textual: discursiva. Ijuí, RS: UNIJUÍ.

MOREIRA, H. e CALEFFE, L.G. (2008). Elaborações e uso de questionários. In: Metodologia da pesquisa para o professor pesquisador. Rio de Janeiro: Lamparina, 95-133.

OLIVEIRA, R.A. de e SILVA, A.P.B. da. A história da Ciência no ensino: diferentes enfoques e suas implicações na compreensão da ciência. In: ENCONTRO NACIONAL DE PESQUISA EM EDUCAÇÃO EM CIÊNCIAS, 8, 2011, Campinas. Anais eletrônicos... Campinas: UNICAMP, 2011. Disponível em: <http://www.nutes.ufrj.br/abrapec/viiienpec/resumos/R0227-1.pdf>. Acesso em: 20 out. 2013.

OLIVEIRA, R.A. e SILVA, A.P.B. História da Ciência e ensino de Física: uma análise metahistórica. In: PEDUZZI, L.O.Q.; MARTINS, A.F.P.; FERREIRA, J.M.H. (Orgs.) Temas de História e Filosofia da Ciência no Ensino. Natal: EDUFRN, 2012, p. 41-64.

PEREIRA, A.I.; AMADOR, F. A história da Ciência em manuais escolares de Ciências da Natureza. REEC, v.6, n.1, 2007, p.191-216. 
PEREIRA, C.L.N. e SILVA, R.R. da. (2009) A história da ciência e o ensino de ciências. Revista Virtual de Gestão de Iniciativas Sociais (GIS), Mar/Edição Especial. Disponível em: < http://www.ltds.ufrj.br/gis/a_historia.htm>. Acesso em: 07 nov. 2013

PESSOA JUNIOR., O. (1996). Quando a abordagem histórica deve ser usada no Ensino de Ciências? Ciência \& Ensino, 1, 4-6.

SAITO, F. (2010). História da Ciência e Ensino: em busca de diálogo entre historiadores e educadores. História da Ciência e Ensino: construindo interfaces, 1, 1-6.

SANTOS, F.M. dos. (2012). Análise de conteúdo: a visão de Laurence Bardin. Revista Eletrônica de Educação, 6, 1 (Resenhas).

TAVARES, L.H.W. (2010). Os tipos de abordagem histórica no ensino: algumas possibilidades encontradas na literatura. História da Ciência e Ensino: construindo interfaces, 2, 14-24.

UNIVERSIDADE ESTADUAL DE MARINGÁ. Conselho Interdepartamental. Centro de Ciências Biológicas. Resolução no 044, de 2010, Maringá, PR, fl. 1-25, out. 2010.

Recebido em: 24/07/2017

Aceito em: 02/08/2017

Endereço para correspondência:

Nome Maíra Luana Santos Souza

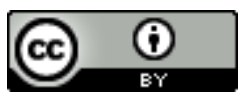

e-mail:mairalsouza@gmail.com 